\title{
COMENTÁRIO EDITORIAL
}

A EVOLUÇÃO RECENTE DA REVISTA IBERO-AMERICANA DE ESTRATÉGIA

Ao longo dos últimos dois anos a Revista Ibero-Americana de Estratégia (RIAE) evoluiu em múltiplas dimensões na sua busca pelo desenvolvimento da pesquisa em estratégia a partir do Brasil. Durante os anos de 2014 e 2015 realizamos diversas mudanças que passaram por melhorias no processo editorial, no formato do periódico, na divulgação dos artigos (inclusive usando as redes sociais), no website que é o interface de contato por excelência com os autores, revisores e leitores. Este tem sido um trabalho evolutivo que tem contado com a colaboração de muitas pessoas que temos de reconhecer.

Para as melhorias que têm sido introduzidas temos de agradecer aos envolvidos. Certamente, os autores merecem o nosso primeiro agradecimento porque compreendemos que têm diversas alternativas de periódicos onde submeter os seus trabalhos e a sua escolha pela RIAE nos privilegia. Aos revisores manifestamos um agradecimento profundo porque
Fernando Antonio Ribeiro Serra Editor Científico RIAE

Universidade Nove de Julho - UNINOVE

Programa de Pós-Graduação em Administração

Manuel Aníbal Silva Portugal Vasconcelos Ferreira

Editor Adjunto RIAE

Universidade Nove de Julho - UNINOVE

Programa de Pós-Graduação em Administração conhecemos bem o tempo, esforço e dedicação que estão envolvidos em fazer um trabalho de avaliação com qualidade. A qualidade das avaliações é importante também para os autores e ajudam a elevar o nível do conhecimento que é gerado na nossa academia. Aos poucos, paulatinamente, aproximamonos dos nossos congêneres europeus e norteamericanos. A RIAE quer contribuir para a qualidade, a maior qualidade dos artigos publicados.

Um terceiro agradecimento para toda a equipe editorial da Uninove que é a face invisível do processo, mas que é fundamental para que tudo decorra na normalidade que pretendemos e para implementar nos processos as mudanças que pretendemos. Extensivo aos demais membros da equipe agradecemos ao Altiéres, pela dedicação e contribuições técnicas, além das sempre bem-vindas sugestões. Agradecemos também à Camila que nos atura e organiza nosso trabalho. É importante ressaltar o apoio dado pela Uninove, em especial do Prof. Emerson Maccari, para 
A Evolução Recente da Revista Ibero-Americana de Estratégia

o desenvolvimento da Revista Ibero-Americana de Estratégia. Não é possível esquecer que na criação e consolidação da RIAE esteve o Professor Doutor Benny Kramer Costa, como Editor-chefe até 2014 desbravando caminhos.

No comentário editorial deste primeiro número de 2016, apresentamos dados e informações que mostram a evolução da RIAE. Com este relatório anual prestamos conta do nosso trabalho aos leitores, autores e revisores do periódico. Também registramos e controlamos os progressos já conseguidos com o intuito de melhorar e contribuir ainda mais para o desenvolvimento da área de estratégia no Brasil. A RIAE manteve o seu status Qualis B2 e continuamos a trabalhar para elevar este nível no futuro possível. Neste comentário também expomos os nossos objetivos, ou melhor, sonhos, visto que o desenvolvimento de um periódico acadêmico é obrigatoriamente um projeto a longo prazo. Não existem atalhos. É preciso seguir um caminho estruturado e com resiliência, ir progredindo na aceitação junto aos leitores e, como consequência, nos rankings de periódicos.

\section{EVOLUÇÃO RECENTE DA REVISTA IBERO- AMERICANA DE ESTRATÉGICA}

Apresentamos alguns dados que refletem parte o progresso da RIAE nos anos recentes de 2012 a 2015 de forma sintética na Tabela 1. Começando pela quantidade de submissões. Havia uma quantidade de artigos acumulados das submissões de 2013. A partir de 2014 a quantidade de submissões reduziu e estabilizou. Um dos motivos desta redução foi a definição do escopo do que entendemos como um periódico de estratégia. Ou seja, praticamente todo o desk reject de 2013 teve a ver com não aderência ao escopo da RIAE, enquanto a parte mais significativa do desk reject de 2014 e 2015 se deveu à qualidade inadequada para seguir para a revisão por pares.

$\mathrm{Na}$ nossa avaliação como editores, a qualidade dos artigos submetidos tem sido melhor. Embora a atividade de revisão por parte dos editores tenha sido rigorosa, a participação dos avaliadores cresceu. Cresceu, não pela quantidade de artigos, necessariamente, mas pelo fato de termos conseguido que os avaliadores estejam fazendo revisões construtivas e mais extensas, de forma a ajudar aos autores, quer o artigo seja rejeitado ou não, com sugestões para que possa ser melhorado. $O$ índice de rejeição de artigos chegou a cerca de $67 \%$.

Tabela 1 - Dados de submissão da RIAE de 2013 a 2015

\begin{tabular}{|c|c|c|c|}
\hline ANO & 2013 & 2014 & 2015 \\
\hline PERIODICIDADE & \multicolumn{3}{|c|}{ Trimestral } \\
\hline $\begin{array}{c}\text { Artigos submetidos no } \\
\text { sistema }\end{array}$ & 219 & 121 & 120 \\
\hline Desk Reject & $93(42,46 \%)$ & $57(47,11 \%)$ & $45(37,5 \%)$ \\
\hline $\begin{array}{c}\text { Artigos avaliados Double } \\
\text { Blind }\end{array}$ & 126 & 64 & 75 \\
\hline$\%$ Artigos aceitos & $31,75 \%$ & $68,75 \%$ & $53,33 \%$ \\
\hline Artigos publicados & 40 & $\begin{array}{l}44 \\
\text { (se for contar com a seção de } \\
\text { Comentário Editorial, } \\
\text { Perspectiva e Resenha) }\end{array}$ & $\begin{array}{l}40 \\
\text { (se for contar com a seção de } \\
\text { Comentário Editorial, } \\
\text { Perspectiva, Artigo } \\
\text { Tecnológico e Resenha) }\end{array}$ \\
\hline Rejeição total & $81,73 \%$ & $63,64 \%$ & $66,67 \%$ \\
\hline
\end{tabular}


$\mathrm{Na}$ Tabela 2 apresentamos outras informações sobre a RIAE. Uma primeira observação é sobre o esforço e cooperação dos avaliadores. O tempo de avaliação e publicação dos artigos caiu para 80 dias, com uma redução de aproximadamente $54 \%$ e $38 \%$ do tempo respectivamente. Acreditamos que este indicador, em conjunto com a qualidade das avaliações, representam o foco que procuramos dar em prestar um serviço de valor para os autores.

Tabela 2 - Tempos de avaliação e submissão

\begin{tabular}{||c|c|c|c|c|}
\hline ANO & $\mathbf{2 0 1 5}$ & $\mathbf{2 0 1 4}$ & $\mathbf{2 0 1 3}$ & $\mathbf{2 0 1 2}$ \\
\hline $\begin{array}{c}\text { tempo de } \\
\text { avaliação (dias) }\end{array}$ & 82 & 237 & 166 & 153 \\
\hline $\begin{array}{c}\text { tempo de } \\
\text { publicação (dias) }\end{array}$ & 80 & 227 & 222 & 213 \\
\hline $\begin{array}{c}\text { redução do tempo } \\
\text { de avaliação }\end{array}$ & $53,6 \%$ & $\begin{array}{c}\text { redução do } \\
\text { tempo de } \\
\text { publicação }\end{array}$ & $37,6 \%$ \\
\hline
\end{tabular}

Também notamos um aumento significativo de usuários cadastrados e crescente de usuários novos. O aumento chegou a $430 \%$ em comparação ao ano de 2012 (Tabela 3). Um dos motivos que provavelmente presidem ao maior interesse na revista é o novo formato da RIAE, que tem ajudado a atrair mais leitores. A revista conta agora com novas seções. Além da usual seção de artigos, criamos em 2015 novas seções com orientações específicas para os autores. Temos a seção de Perspectivas, Artigos, Artigos Tecnológicos e Resenhas. Na seção de perspectivas trazemos contribuições com olhares novos ou críticos, além de revisões bibliográficas ou bibliométricas dos temas diretamente relacionados com a pesquisa em estratégia, que é o foco da revista. Temos a seção tradicional de artigos para trabalhos teóricos, empíricos quantitativos ou qualitativos. Mas, criamos uma seção para Artigos Tecnológicos que possibilitam as contribuições orientadas para a prática. Em parte, esta seção também surge como resultado de uma parte das submissões que recebemos e que tem vindo a aumentar, talvez em parte devido à criação de mestrados profissionais. Finalmente, há uma seção para Resenhas Bibliográficas que era comum em muitas revistas, mas que se tem vindo a perder. No entanto, estas resenhas, se de obras relevantes é especialmente interessante para nossos alunos de mestrado e doutorado. Buscamos aqui publicar resenhas de livros relevantes e clássicos disponibilizando, assim, uma primeira abordagem aos potenciais leitores. Apesar da sua importância e muitas vezes alusão a estes livros, verificamos que muitos pesquisadores que os citam efetivamente não os leram. Além destas seções, temos apresentado comentários editoriais que têm focado, essencialmente, questões de pesquisa e publicação em Administração, com o intuito de contribuir para a melhoria e organização de artigos acadêmicos. Estes comentários têm sido arquivados na aba How to publish (or Perish?) no site da RIAE, ficando assim disponíveis para consulta (ver em: http://www.revistaiberoamericana.org/ojs/index.php/ib ero/pages/view/publish\%20or\%20perish). 
A Evolução Recente da Revista Ibero-Americana de Estratégia

Tabela 3 - Evolução dos usuários cadastrados

\begin{tabular}{|l|r|r|}
\hline \multirow{2}{*}{ País } & \multicolumn{2}{c|}{ Visualizações } \\
\cline { 2 - 3 } & Ruantidade & \multicolumn{1}{c|}{$\%$} \\
\hline Brasil & 10007 & $85,41 \%$ \\
\hline Reino Unido & 158 & $1,35 \%$ \\
\hline EUA & 123 & $1,05 \%$ \\
\hline Portugal & 175 & $1,49 \%$ \\
\hline Mexico & 243 & $2,07 \%$ \\
\hline Índia & 145 & $1,24 \%$ \\
\hline Austrália & 40 & $0,34 \%$ \\
\hline Argentina & 109 & $0,93 \%$ \\
\hline Tunísia & 79 & $0,67 \%$ \\
\hline Alemanha & 22 & $0,19 \%$ \\
\hline Total & $\mathbf{1 1 7 1 7}$ & $\mathbf{1 0 0 , 0 0 \%}$ \\
\hline
\end{tabular}

A submissão de artigos e, em especial, a busca por artigos publicados na RIAE tem aumentado por pesquisadores estrangeiros. Há vários fatores que contribuirão para este efeito entre os quais acreditamos que estejam três em especial: a divulgação da revista pelo canal da Iberoamerican Academy of Management, a tradução do site para o idioma inglês e também do título da revista (Iberoamerican Journal of Strategic
Management), e por ter crescido o número de artigos publicados na RIAE em inglês e espanhol. A Tabela 4 apresenta os acessos por país de origem em 2016, considerando que eram incipientes nos anos anteriores.

Tabela 4 - Acessos por país aos artigos da RIAE

\begin{tabular}{|c|c|c|c|c|}
\hline ANO & 2015 & 2014 & 2013 & 2012 \\
\hline $\begin{array}{c}\text { usuários } \\
\text { cadastrados }\end{array}$ & 5003 & 2649 & 1633 & 1054 \\
\hline $\begin{array}{c}\text { usuários } \\
\text { novos }\end{array}$ & 2354 & 1016 & 579 & 547 \\
\hline $\begin{array}{c}\text { \% aumento de } \\
\text { usuários }\end{array}$ & $430,3 \%$ & & & \\
\hline
\end{tabular}

Fonte: Google Analytics, 2016.

Outro indicador importante do crescimento do impacto da RIAE é o da base Spell. A RIAE está no primeiro quartil dos periódicos que compõem a base (http://www.spell.org.br/impacto). Não descuidamos da relevância que é, em primeira instância, o interesse dos pesquisadores nos artigos que temos publicado. $\mathrm{O}$ melhor indicador deste interesse é o crescimento do número de downloads e de citações aos artigos em outras bases.

\section{O FUTURO: SONHOS E OBJETIVOS}

O futuro está repleto de desafios. Sem dúvida o nosso sonho é tornar a RIAE um dos principais periódicos nacionais e com impacto internacional. Este é um desafio que depende não apenas da equipe editorial, mas, também, do apoio institucional e da colaboração e do interesse contínuo e crescente de autores, revisores e leitores, nacionais e estrangeiros. 
Enquanto trabalhamos na melhoria da RIAE temos consciência que os outros editores de outros periódicos também trabalham para melhorar os seus periódicos. Assim, as metas são móveis.

Como objetivos para o ano de 2016, pretendemos continuar reduzindo o tempo médio de avaliação dos artigos submetidos e trabalhar com os revisores para termos cada vez mais e melhores avaliações construtivas. Com esta orientação assumimos que não temos na RIAE uma lógica avaliativa, mas sim construtiva e os autores mesmo que tenham os seus artigos rejeitados na RIAE obterão um conjunto de recomendações que poderão integrar nos seus artigos para uma submissão futura. Fundamentalmente assumimos a orientação de contribuir para a ciência em Administração brasileira. Ou seja, pretendemos trabalhar com os autores para melhorar a qualidade dos seus artigos.

Continuaremos a focar os comentários editoriais voltados para o aprimoramento da qualidade dos artigos, e como materiais de orientação para pesquisadores menos experientes - onde estimamos que estes sejam, pelo menos primordialmente, estudantes de mestrado e doutorado. Os comentários editoriais não visam apenas ser um guia e também pretendem, pelo menos em alguns casos, contribuir para uma reflexão mais profunda do que será construir um pensamento em estratégia no Brasil.

$\mathrm{Na}$ RIAE aceitamos a crescente orientação para a pesquisa que aborde fenômenos, seguindo uma tendência que cresce, apesar de não ser ainda seguida pelos periódicos líderes, e que dê mais significado à pesquisa em administração, especificamente em Estratégia. Mas, esta orientação necessita ser ponderada com o foco teórico, seguindo os melhores padrões internacionais. $\mathrm{O}$ estudo dos fenômenos necessita ser embasada em teoria sólida. No que se refere à orientação metodológica a RIAE continua a aceitar todo o tipo de artigos, mesmo notando que a tendência internacional em estratégia não seja qualitativa. O fundamental é que a metodologia seja adequada, ajustada ao que se estuda e bem executada.

Adicionalmente, ao longo dos anos a RIAE tem apoiado encontros e congressos de administração, para que trabalhos selecionados possam seguir em fasttrack. O fast-track não implica aceitação do artigo, mas apenas um processo que a equipe editorial acompanha para ser, se possível, célere. Neste sentido apoiamos o retorno do ELBE - Encontro Luso-brasileiro de Estratégia, neste ano que pensamos poderá ocorrer em simultâneo com o SINGEP-S2IS, promovido pela e na Uninove.

Em 2016 continuaremos a reforçar a divulgação dos artigos de modo a que os autores tenham a maior exposição dos seus trabalhos. Em 2015, ainda que de forma experimental, e pela iniciativa da equipe de suporte editorial, demos início a uma maior divulgação da RIAE, principalmente pelo Facebook e Twitter. Em 2016, pretendemos reforçar a divulgação. Além da divulgação abrangente, pretendemos incentivar que mais autores e revisores estrangeiro possam ter interesse em submeter e colaborar com a RIAE, e cada vez mais considerando o contexto brasileiro e latino-americano, ou empresas brasileiras e latino-americanas.

Fica ainda o sonho de poder ter um dia os artigos publicados em português, espanhol e inglês no website. Embora tenha crescido a publicação de artigos em idioma estrangeiro, acreditamos que ter uma versão do texto em português é importante. Em todo o caso, é previsível que, de modo gradual, tenhamos mais artigos em inglês.

Finalizando gostaríamos novamente de enfatizar nosso agradecimento a todos que têm apoiado e ajudado no desenvolvimento da RIAE e nossa intenção de continuar seguindo na busca de tornar o nosso periódico positivamente mais influente e relevante para a academia nacional e como veículo de divulgação da pesquisa brasileira em estratégia. 